Acta Universitatis Wratislaviensis • No 3869

Literatura i Kultura Popularna XXIV, Wrocław 2018

DOI: $10.19195 / 0867-7441.24 .8$

\author{
Marta Stańczyk \\ ORCID: 0000-0002-1698-7845 \\ Uniwersytet Jagielloński
}

\title{
Liberté, égalité, sororité. Kobiece gatunki cielesne i francuskie ,ekstremistki”
}

Słowa kluczowe: nowy ekstremizm francuski, Linda Williams, gatunki cielesne, kino kobiet

Keywords: New French Extremity, Linda Williams, body genres, women's cinema

W tekście Film bodies: Gender, genre, and excess ${ }^{1}$ Linda Williams rozwija kategorię ,gatunków cielesnych” (body genres), do których zalicza melodramat, horror i film pornograficzny. Gatunki te zmieniają usankcjonowany, tradycyjny sposób odbioru filmu, intensyfikując go w znaczący sposób. Analiza formalna i tekstualna pozwoliła badaczce na wyróżnienie źródeł wisceralnego oddziaływania na widza, lecz w centrum tej refleksji znajdują się ideologiczne funkcje takich struktur opowiadania, które opierają się na afektywnym ekscesie. Medium somatycznego pobudzenia jest bowiem genderowo zdeterminowane - jest to ciało kobiece, uprzedmiotowione i ukierunkowane na zaspokajanie głównie męskiej przyjemności. Mimo że Williams odrzuca model identyfikacji, zdaje się kontynuować myśl zainicjowaną przez Laurę Mulvey w kanonicznym tekście Przyjemność wzrokowa a kino narracyjne ${ }^{2}$. W odróżnieniu jednak od Brytyjki autorka Film bodies wskazuje na sposoby subwersywnego potraktowania gatunkowego reżimu.

„Brzemię reprezentacji”3 może zostać przełamane za sprawą silnego afektywnego oddziaływania towarzyszącego podważeniu cielesnych kodów zarówno

${ }^{1}$ L. Williams, Film bodies: gender, genre, and excess, „Film Quarterly” 1991, nr 4, s. 2-13.

${ }^{2}$ Polskie tłumaczenie tekstu Mulvey można znaleźć chociażby, [w:] eadem, Przyjemność wzrokowa a kino narracyjne, przeł. J. Mach, [w:] eadem, Do utraty wzroku: Wybór tekstów, red. K. Kuc, L. Thompson, Kraków-Warszawa 2010, s. 33-47.

${ }^{3}$ B. Nichols, Film Theory and the Revolt Against Narratives, [w:] Reinventing Film Studies, red. Ch. Gledhill, L. Williams, Arnold 2000, s. 43. 
wizualnych, jak i audialnych. Ich dekonstrukcja jest spiritus movens dzieł utożsamianych z nurtem ekstremizmu francuskiego, który „chce złamać każde tabu, brodzić w spienionych spermą rzekach wnętrzności, wypełnić każdy kadr ciałem, ponętnym lub odrażającym, i poddać je wszystkim rodzajom penetracji, okaleczenia i profanacji"4. Dokonuje on transgresji nie tylko na poziomie kulturowym, lecz także społeczno-politycznym, co doskonale obrazują feminizujące dzieła Virginie Despentes, Mariny de Van czy Julie Ducournau, dokonujących autopsji na stereotypowych przedstawieniach płci, odkrywających na nowo doświadczenie ucieleśnienia oraz rozkładających na czynniki pierwsze gatunki cielesne poprzez podkreślenie elementów dyskursywnych. W końcu autotematyczną maksymę Gaspara Noé z Love (Francja-Belgia 2015) o filmach składających się z krwi, łez i spermy można odnieść bezpośrednio do horroru, melodramatu i filmu pornograficznego, swoiście unerwiających konwencje ekstremizmu francuskiego.

\section{Jestem, więc myślę}

Według Ricka Altmana ,gatunek” to konstrukt łączący relacje między producentami, twórcami i widzem (aporie budują system oczekiwań) ${ }^{5}$. Gatunki filmowe mają charakter dyskursywny; nie da się ich w prosty sposób wywieść z badań literaturoznawczych, jeszcze więcej problemu dostarcza określenie ich twórcy, a współcześnie nawet granic. Daniel Chandler zauważył, że demarkacja i definicja stają się coraz trudniejsze — można powtórzyć za nim, że słuszniejsze jest mówienie nie o systemie, a o procesie systematyzacyjnym ${ }^{6}$. Równie istotna zdaje się dyskursywna dynamika widza i tekstu, splecionych we wstędze Möbiusa, relacji wiążącej intencję nadawania $\mathrm{z}$ horyzontem oczekiwań odbiorców ${ }^{7}$. W takim kontekście można umiejscowić artykuł Williams. Jej zainteresowanie cielesnym rezonansem wywoływanym przez niektóre gatunki oraz inkorporacja subiektywnej perspektywy - własnego doświadczenia filmowego - stały się podwalinami wstecznego uznania jej koncepcji za wpisującą się w ramy sensuous theory. Chociaż zatem tekst osadzony jest w kontekście psychoanalitycznym, pozwalam sobie na akcentowanie wątków związanych z (ucieleśnionym) odbiorem.

Badaczka zaczyna swój opis od wrażeń swoich i swojego syna — oboje żywo reagowali na sceny, które posługiwały się intensywną doznaniowością wyrywającą ich z czysto poznawczej eksploracji dzieła filmowego. To afektywne,

4 J. Quandt, Flesh and blood: Sex and violence in recent French cinema, „ArtForum” 2004, nr 2, https://www.thefreelibrary.com/Flesh+\%26+blood $\% 3 \mathrm{~A}+$ sex + and+violence+in+recent+French+ cinema.-a0113389507 (dostęp: 4.06.2017).

5 Zob. R. Altman, Gatunki filmowe, przeł. M. Zawadzka, Warszawa 2012.

${ }^{6}$ D. Chandler, An Introduction to Genre Theory, http://www.aber.ac.uk/media/Documents/ intgenre/chandler_genre_theory.pdf, s. 3 (dostęp: 5.05.2017).

${ }^{7}$ Zob. R. Altman, op. cit. 
„obsceniczne"8 przekroczenie na gruncie reprezentacji przemocy (horror), seksu (film pornograficzny) bądź emocji (melodramat) wywołuje odpowiednio strach/ obrzydzenie, podniecenie lub wzruszenie. Gatunki cielesne - taką nazwę Williams przejmuje od Carol J. Clover ${ }^{9}$ — są ekscesem w klasycznej narracji. Do systemu zdominowanego przez linearność, przyczynowo-skutkowość i ekonomię opowiadania wprowadzają logikę spektaklu. W taki ponadgatunkowy sposób można opisać melodramat (lekceważenie stylu realistycznego, spektakl jako wyrwa w narracji, intensywne, wręcz prymitywne emocje, epizodyczność, nieumotywowane zdarzenia, podkreślane paralele czy repetytywność ${ }^{10}$, czego autorka Film bodies jest świadoma, lecz decyduje się na klasyczne rozumienie tej formuły opowiadania, którą z horrorem i filmem pornograficznym łączą trzy cechy: przedstawiają (1) ciało jako spektakl; (2) ciało silnie poruszone, znajdujące się w stanie pewnej formy ekstazy (co jest widoczne chociażby poprzez spazmy bólu lub rozkoszy, wydostawanie się poza artykulację językową); (3) ciało kobiety, które stanowi podstawę ucieleśnienia przyjemności, strachu, bólu i smutku, jest „poruszone i poruszające”"11. To ucieleśnienie, jak sądzi Williams, jest źródłem niskiego statusu kulturowego tych trzech gatunków, które wymuszają na ciele widza asymilację z przeżyciami na ekranie (mimikra zastępuje identyfikację), uniemożliwiając dystans i intelektualną refleksję nad filmem, a przez to również manipulując reakcjami odbiorców (,tekstualny gwałt"). Autorka tekstu opisuje genderowe uwikłanie gatunków cielesnych poprzez struktury perwersji i fantazji, lecz stara się sproblematyzować kwestię wiktymizacji pojawiających się w nich postaci, a raczej kobiecych ciał. Przywołuje między innymi male weepie (przykładowo Sprawa Kramerów [Kramer vs. Kramer, reż. Robert Benton, USA 1979], lecz także Jutro będziemy szczęśliwi [Demain tout commence, reż. Hugo Gélin, Francja-WB 2016) czy 35 kieliszków rumu [35 rhums, reż. Claire Denis, Francja-Niemcy 2008]), slashery z androgyniczną final girl (Blady strach [Haute Tension, reż. Alexandre Aja, Francja-Włochy-Rumunia 2003] to film, który doprowadził do skrajności konserwatywny wymiar tej postaci) oraz nowe kategorie filmów pornograficznych (nacisk należałoby położyć na tendencje prokobiece w femme porn i lesbian porn, lecz także rozwój hard core art film i sekspozytywnych filmów Anne Biller).

Ustalenia Williams nie są nowatorskie na poziomie interpretacji poszczególnych gatunków. Sama przywołuje wiele rozważań na temat melodramatu i hor-

${ }^{8}$ L. Williams, op. cit., s. 2.

9 Zob. C.J. Clover, Her body, himself: Gender in the slasher film, „Representations” 18, 1987, nr 20, Clover opisywała w ten sposób horrory i filmy pornograficzne.

10 Zob. np. L. Mulvey, Kino zwłoki, przeł. K. Klimek, J. Majmurek, [w:] eadem, Do utraty wzroku. Wybór tekstów, Kraków-Warszawa 2010; B. Langford, Film Genre: Hollywood and Beyond, Edinburgh 2005; P. Brook, The Melodramatic Imagination: Balzac, Henry James, and the Mode of Excess, London 1976.

${ }^{11}$ L. Williams, op. cit., s. 4. 
roru, do których należałoby dodać inne ważne ustalenia, jak chociażby — przy wszystkich metodologicznych różnicach - Noëla Carrolla. W Filozofii horroru albo paradoksach uczuć wskazał za Arystotelesem, że gatunek służy wywołaniu pewnego efektu emocjonalnego; w wypadku horroru jest to strach połączony $\mathrm{z}$ obrzydzeniem, a raczej art-groza polegająca na synchronizacji własnych reakcji z zachowaniem bohatera pozytywnego, lecz także nie na pełnej identyfikacji ${ }^{12}$, a raczej - jak pisała również Williams - asymilacji ich sytuacji. Kwestię pornografii badaczka rozwinie w innych tekstach, na przykład w wydanym w Polsce Hard core. Władza, przyjemność $i$, szaleństwo widzialnego"13, jednak warto także przywołać rozważania Magdy Szcześniak zestawiającej sposoby reprezentacji kobiecego ciała w tego typu produkcjach z teorią symulakrów. „Pornografia jest gatunkiem prześladowanym przez przyjemność kobiecą, której nie da się pokazać"14 - rozwiązaniem staje się estetyka nadmiaru, ale „przez nadmiar pornografia przestaje być gatunkiem o ciele, a staje się opowieścią o znakach cielesności. [...] Te obsesyjne zbliżenia nacechowanych erotycznie części ciała często nadają filmowi nierealny wymiar" 15 .

Przywołuję ustalenia młodej badaczki nie bez przyczyny: ukazują one faktyczne znaczenie tekstu Williams. Po pierwsze, Film Bodies jest jednym z artykułów inicjujących paradygmat antyokulocentryczny, somatyczny, który zastępuje figurę widza-voyeura figurą widza doświadczającego, a hegemonię oka - afektywnym odbiorem. Po drugie, opisywane przez Williams responsywne ciało staje się źródłem znaczenia, otwierając odbiorców na pozaracjonalną logikę. Jak pisała Martine Beugnet,

otworzyć się na sensualną świadomość i pozwolić na bycie afektywnie dotkniętym przez dzieło sztuki lub spektakl wiąże się z wyrzeczeniem się pełnej kontroli; racjonalny dystans zostaje zastąpiony przez intensywność i chaos ${ }^{16}$

— one też są sensotwórcze i nadają filmom krytyczny wymiar, co pokazują twórcy związani z nowym ekstremizmem francuskim.

${ }^{12}$ N. Carroll, Filozofia horroru albo paradoksy uczuć, przeł. M. Przylipiak, Gdańsk 2004, s. $35-36$.

${ }^{13}$ L. Williams, Hard core: Władza, przyjemność i ,, szaleństwo widzialnego”, przeł. J. Burzyńska, I. Hansz, M. Wojtyna, Gdańsk 2012.

${ }^{14}$ M. Szcześniak, Symulakryczna przyjemność. Obrazy kobiecej przyjemności w filmach pornograficznych, „Kultura Popularna” 2009, nr 1, s. 69.

15 Ibidem, s. 70.

${ }^{16}$ M. Beugnet, Cinema and Sensation: French Film and the Art of Transgression, Edinburgh 2007, s. 3. Ten opis przypomina działanie afektów w definicji Briana Massumiego. Według niego afekt jest nieświadomy, niesubiektywny/przedsubiektywny, nieznaczący, nieklasyfikowany, intensywny, przekraczający naszą podmiotowość. Zob. idem, Autonomia afektu, przeł. A. Lipszyc, „Teksty Drugie” 2013, nr 6. 


\section{Filmy z krwi i kości}

Pojawienie się takich twórców, jak Bruno Dumont, Philippe Grandrieux czy Gaspar Noé, z nonszalancją niszczących przyjemność widza poprzez hiperbolicznie wisceralną poetykę swoich filmów, uznane było przez część krytyków - na przykład Jamesa Quandta czy Mattiasa Freya - za czystą prowokację skażoną ideologiczną pustką. Jednak funkcje estetyki ich filmów nie sprowadzały się do czystej profanacji, umiejscawiając się we francuskiej tradycji kontrkulturowej ${ }^{17}$, kontekście społecznym Francji przełomu wieków ${ }^{18}$ oraz studiach nad upolitycznionym afektem. Steven Shaviro w 1993 roku pisał: „Film posiada radykalny potencjał przekraczania społecznych hierarchii i dekompozycji relacji władzy za sprawą jego ekstremalnych możliwości uwodzenia i przemocy"19, a to z kolei wynika z samej natury naszego ciała, które tylko cienka warstwa skóry dzieli od mięsa (angielskie rozróżnienie na body i flesh lub francuskie na corps i chair). Zainspirowana tą myślą Jennifer M. Barker pisała o „zaraźliwym kontakcie”20 — definiuje on nie tylko relacje fabularne, lecz przede wszystkim spotkanie, konfrontację widza z filmem.

Nowy ekstremizm francuski to eklektyczny nurt, ale do elementów łączących jego twórców należy z pewnością przełamywanie tabu związanego z reprezentacją cielesności. Ciało staje się powierzchnią komunikacyjną. Z jednej strony dotyk staje się jedynym sposobem wyrażenia bliskości — w Love Noé buduje

${ }^{17}$ Nowy ekstremizm francuski można opisywać w kontekście tekstów de Sade'a, Baudelaire'a czy Bataille'a, tradycji surrealistycznej łączącej w transgresyjny sposób „wysokie” z „niskim”, teatru okrucieństwa Artauda czy takich filmów, jak Pieśń miłości (Un chant d'amour, reż. Jean Genet, Francja 1950), Oczy bez twarzy (Les yeux sans visage, reż. Georges Franju, Francja-Włochy 1960) czy Weekend (Weekend, reż. Jean-Luc Godard, Francja-Włochy 1967).

${ }^{18}$ Şirin Fulya Erensoy opisywała dynamiczny rozwój francuskiego horroru po roku 2000 w kontekście powrotu represjonowanego, w tym przypadku chodziło przede wszystkim o kwestie genderowe oraz status imigrantów. Niska frekwencja na wyborach prezydenckich w 2002 roku pokazała, że ludzie przestali wierzyć w zmianę, zanurzając się w poczuciu rozczarowania. Napięcie zwiększyła polityka wewnętrzna Nicolasa Sarkozy’ego, która pośrednio doprowadziła do zamieszek z 2005 roku. Ich skutkiem było dalsze zaostrzenie polityki migracyjnej, a co za tym idzie - postępująca polaryzacja społeczna, rasizm i nacjonalizm. Wątek zamieszek pojawiał się w Najściu (À l'intérieur, reż. Alexandre Bustillo, Julien Maury, Francja 2007) oraz Frontière(s) (reż. Xavier Gens, Francja-Szwajcaria 2007), podczas gdy Blady strach ukazał lęki przed rozpadem heteronormatywnej rodziny. Rzekomo lewicowa polityka prezydenta François Hollande'a pogłębiła ksenofobiczne myślenie, ograniczanie definicji narodowej tożsamości, a przez to kolejne ataki terrorystyczne w 2015 roku, jednak zmiany społeczne w drugiej dekadzie XXI wieku i tak nie znalazły jeszcze ekspresji gatunkowej (Şirin Fulya Erensoy twierdzi, że twórcy z poprzedniej dekady zostali wchłonięci przez Hollywood). Zob. Ş.F. Erensoy, The reflection of contemporary anxieties in the contemporary french horror cycle, http://framescinemajournal.com/article/the-reflection-of-contemporary-anxieties-in-the-contemporary-french-horror-cycle/ (dostęp: 25.05.2017).

19 S. Shaviro, The Cinematic Body, Minneapolis 1993, s. 64.

20 J.M. Barker, The Tactile Eye: Touch and the Cinematic Experience, Berkeley-Los Angeles-London 2009, s. 47. 
film o tytułowym uczuciu, koncentrując się na sferze seksu i erotyki, w Życiu Jezusa (La vie de Jésus, Francja 1997) czy Hadewijch (Francja 2009) bohaterowie Dumonta tęsknią za ukochanym ciałem (odpowiednio: dziewczyny i Jezusa), lecz chwile zbliżeń - co pokazuje pozbawione nadziei oddanie się Barbe we Flandrii (Flandres, Francja 2006) lub zwierzęco ukazane stosunki seksualne w Twentynine Palms (Francja-Niemcy-Włochy 2003) i Ludzkości (L’humanité, Francja 1999) - utwierdzają ich ostatecznie w niemożności kontaktu. Z drugiej strony ciało staje się miejscem ekspresji frustracji, gniewu czy agresji, zmieniając się w mięso poddawane aktom przemocy.

Brutalność obu perspektyw zostaje zaakcentowana przez Grandrieux zwłaszcza w debiutanckim filmie pełnometrażowym Sombre (Francja 1998), w którym łączy przyjemność ze strachem, uczucie rozkoszy i podniecenia z zadawaniem bólu: seryjny morderca prowokuje zbliżenia seksualne, a przed samym stosunkiem przesuwa dłonie na szyję kobiety, dławiąc jej krzyk palcem wciskanym w gardło. Zresztą wyznanie reżysera: ,[Film to - M.S.] cielesne, fizyczne, ludzkie doświadczenie. Interesuje mnie kino doznań. Porusza mnie to, co film przekazuje jako doznanie - nie tylko emocję - poprzez obrazy, dźwięki, montaż, ciała, aktorów..." może stanowić motto pozostałych twórców wiązanych z ekstremizmem francuskim i jest podstawą częstego klasyfikowania go do szerszej grupy dzieł określanych jako cinema of sensation. Martine Beugnet w Cinema and sensation: Contemporary french film and cinematic corporeality pisała:

Uważam, że taki sposób filmowania, który destabilizuje narrację i percepcję wizualną, a także podaje w wątpliwość możliwość zdystansowanego, obiektywnego podejścia do diegezy, wspiera odmienny sposób odbioru związany z materialnością medium, z filmem jako zdarzeniem samym w sobie ${ }^{21}$.

Obie sfery — przemocy i seksu — ukazywane są w eksplicytny, podkreślający fizjologiczność sposób, poprzez który ciało zazwyczaj jest uprzedmiotowione, stając się rozczarowującą, zdehumanizowaną wiązką tkanek, mięśni, krwi i kości. Ta dekonstrukcja przenosi się na poziom narracji i gatunku — ekstremizm francuski zaciera konwencje, jednak odwołuje się w oczywisty sposób do gatunków cielesnych, przede wszystkim horroru (nie ma wątpliwości, że jest to body horror, gore czy nawet torture porn) i filmu pornograficznego. Przypomina przez to kino eksploatacji. Mattias Frey uwydatnił ten aspekt, porównując europejskie, arthouse'owe „kino ekstremalne” do tak zwanego erudite skin flicks ${ }^{22}$ europejskich produkcji z lat 60 . XX wieku, zdobywających widzów poprzez podkreślenie graficznych scen seksu czy przemocy. Autor Extreme Cinema: The Transgressive Rhetoric of Today's Art Film Culture podkreśla jednak — jakkolwiek można wy-

${ }^{21}$ M. Beugnet, Cinema and sensation: Contemporary french Film and cinematic corporeality, „Paragraph” 2008, nr 2, s. 175.

${ }_{22}$ M. Frey, Extreme Cinema: The Transgressive Rhetoric of Today's Art Film Culture, New Brunswick-New Jersey-London 2016, s. 5. 
czuć w tym sporą dozę sceptycyzmu — że transgresja służy dystynkcji, separacji od kina mainstreamowego, akademickiego stylu ${ }^{23}$, ale też na przykład pornografii. Retoryka „ekstremistów” opiera się na artystycznej tożsamości, estetycznej wartości i moralnym agnostycyzmie ${ }^{24}$, które osiąga się poprzez antykonsumpcyjne odebranie scenom przemocy waloru rozrywkowego, a scenom seksu funkcji stymulującej podniecenie. Równie często wyróżnia się dyskurs realizmu, jednak w wypadku nowego ekstremizmu francuskiego istotniejsze zdają się autoreferencyjność i metatekstualność, naznaczone refleksją filozoficzną oraz demitologizującą intencją.

Te zabiegi sprawiają, że uwypuklona zostaje obecność widza. Tanya Horeck i Tina Kendall we wstępie do The New Extremism in Cinema: From France to Europe podkreślają, że jedną z najważniejszych cech dystynktywnych nowego ekstremizmu francuskiego jest zwiększanie zmysłowego i afektywnego zaangażowania, a przez to dekonstrukcja odbioru, konfrontacja $\mathrm{z}$ widzem, zainicjowanie „ucieleśnionego dialogu”25. Takie zabiegi poprzez zmysłowe oddziaływanie aktywizują widza, akcentując jednocześnie krytyczny, polityczny potencjał filmów wiązanych z tym nurtem. Przełamywanie ograniczeń języka (filmu) spotyka się w tym miejscu $\mathrm{z}$ feminizmem.

\section{Anatomia feminizmu}

Obie tendencje - ekstremizm oraz myśl feministyczną — reprezentuje powiększająca się cały czas grupa reżyserek - najważniejsze z nich to: Virginia Despentes, Claire Denis, Marina de Van, Catherine Breillat, a w ostatnich latach także Lucile Hadžihalilović i Julia Ducournau. W ich filmach dochodzi do transgresji kinowego fetyszu, pojęcia krytycznie opracowanego przez teorie feministyczne zauważające, że kobiece ciało na ekranie jest uprzedmiotowione i służy męskiej przyjemności. Feminizm korporalny odchodzi od reprezentacji silnie naznaczonej technikami wizualnymi patriarchalnej represji w stronę ucieleśnionego doświadczenia; odrzuca feministyczną nieufność w stosunku do ciała. Ciało staje się narzędziem politycznym, wpisując się w tezy Claire Johnston postawione w tekście Kino kobiece jako kino buntu:

Możemy [jako reżyserki - M.S.] rzucić wyzwanie, rozwijając środki służące badaniu męskiego kina burżuazyjnego. Co więcej, pragnienie zmiany może dojść do głosu tylko w efekcie odwołania się do fantazji. [...] Wszelka rewolucyjna strategia musi rzucić wyzwanie

${ }^{23}$ Dlatego z grona ekstremistów wykluczam m.in. Bertranda Bonello, który korzysta z cielesnej reprezentacji, pozostając jednak cyzelującym formę stylistą, kładącym mniejszy nacisk na kwestię pozaestetycznych doświadczeń widza.

24 Zob. M. Frey, op. cit., s. 23.

25 T. Horeck, T. Kendall, Introduction, [w:] The New Extremism in Cinema: From France to Europe, red. T. Horeck, T. Kendall, Edinburgh 2011, s. 7. 
opisywaniu rzeczywistości; a także należy zbadać język kina opisującego rzeczywistość, by spowodować zerwanie między ideologią a tekstem ${ }^{26}$.

Fundamenty pod powstanie feminizmu korporalnego stworzyła Luce Irigaray, twierdząc, że mężczyzna traktowany jest jako uniwersalna norma, więc kobietę opisuje się poprzez cielesny brak. Jednak zarówno Irigaray, jak i jej kontynuatorki (między innymi Christine Battersby, Abigail Bray i Claire Colebrook) uznają, że tożsamość powstaje właśnie $\mathrm{z}$ tego lekceważonego ciała czy właściwie „wariacji na temat ludzkiego ciała" 27 . Dlatego przywrócono do feminizmu korporalny dyskurs, którego główną przedstawicielką pozostaje Elizabeth Grosz ${ }^{28}$. Badaczka ta uważa, że należy wydostać ciało poza dualistyczne podziały, ponieważ są one redukcjonistyczne w próbie ujęcia problemu relacji ciała z umysłem, a także ,ja” z innym i ze światem. Dlatego konstruuje model ,podmiotowości w kategoriach prymatu korporalności, która patrzy na subiektywność nie wedle modelu ukrycia czy głębi, ale w kategoriach powierzchni" 29 . Grosz odrzuca utożsamianie tylko jednej płci z kategorią cielesności, podporządkowanie ciała sferze biologii (zawsze zdeterminowane jest ono również przez kulturowe wpływy ${ }^{30}$ ), a tym bardziej możliwość stworzenia jakiejkolwiek normy (ideałem pozostaje pluralizm normatywny, nieredukowalna różnica, ,przekształcenie jednego w drugie, przejście, wektor, niekontrolowany prąd wnętrza w kierunku zewnętrza i zewnętrza w kierunku wnętrza" ${ }^{31}$ ).

Poszukiwania Grosz mają charakter niemalże nietzscheański. Ciało w jej ujęciu jest aktywnie zaangażowane $\mathrm{w}$ proces zmiany i transformacji, odrzuca konstytuowanie się tożsamości poprzez spojrzenie innego, niweluje zresztą znaczenie samej tożsamości jako zdeterminowanej przez społeczno-kulturowe wartościowanie: „Nie jestem tym, co inni we mnie widzą, jestem tym, co robię, co produkuję. Staję się zgodnie z tym, co robię, nie zgodnie z tym, kim jestem"32.

${ }^{26}$ C. Johnston, Kino kobiece jako kino buntu, przeł. A. Helman, „Film na Świecie” 1990, nr 1, s. 18.

${ }^{27}$ M. Rogowska-Stangret, Ciało - poza Innościa i Tożsamością, Gdańsk 2016.

${ }^{28}$ Należałoby dodać fenomenologię feministyczną, której głównymi przedstawicielkami są Jenny Chamarette, Elizabeth Stephens oraz Iris Marion Young, jednak ich rozważania przekraczają zakres refleksji gatunkowej.

${ }^{29}$ E. Grosz, Volatile Bodies: Toward a Corporeal Feminism. Podaję za: M. Rogowska-Stangret, op. cit.

${ }^{30}$ Dwoistość ciała zaznacza też Grosz w definicji z książki Space, Time, and Perversion: Essays on the Politics of Bodies: „ciało [...] konkretna, materialna, ożywiona organizacja tkanki mięsnej, organów, nerwów i struktury kostnej, które zyskują jedność, spójność i formę poprzez psychiczne i społeczne inskrypcje na [jego - M.S.] powierzchni” (zob. E. Grosz, Bodies-Cities, [w:] eadem, Space, Time, and Perversion: Essays on the Politics of Bodies, New York-London 1995, s. 104. Podaję za: M. Rogowska-Stangret, op. cit.).

${ }^{31}$ E. Grosz, Volatile Bodies...

32 E. Grosz, Becoming Undone: Darwinian Reflections on Life, Politics, and Art. Podaję za: M. Rogowska-Stangret, op. cit. 
Rogowska-Stangret po skrupulatnej analizie koncepcji australijskiej badaczki tak ocenia jej filozofię i politykę:

Rezygnuje ona [Grosz - M.S.] z tożsamości, rezygnuje z refleksji nad tym, kim jestem, na rzecz działania, na rzecz pytania o to, co mogę zrobić, jak mogę spotęgować własną aktywność, z czym i z kim jeszcze się połączyć, jakimi nieoczekiwanymi spotkaniami cieszyć. [...] Podmiotowość staje się rozbita, ludzkość staje się pozaludzka, ja staje się anonimowe, a tożsamość staje się różnicą. Dzieje się to dzięki potencjom tkwiącym w ciele, które nie jest nieuchwytne z powodu tkwiącej w nim tajemnicy, czegoś, co wymyka się ludzkiemu poznaniu, jest nieuchwytne, bo prowadzi do zaskakujących rozwiązań, eksperymentów, jest otwarte na nieprzewidywalne alianse, spontanicznie reaguje na różne formy opresji, wytwarza wiele propozycji życiowych strategii, nie lęka się tego, że część z nich zostanie odrzucona, próbuje dalej, w nieskończoność powoływać do życia to, co nowe $\mathrm{e}^{33}$.

Ta progresywna polityka umiejscawia eksplorację cielesnych doświadczeń przez „ekstremistki” francuskie na pozycjach związanych z negocjacją i oporem. Brodzenie w rzekach wnętrzności, jak chciał Quandt, proponuje nową epistemologię — antyokulocentryczną i feministyczną.

\section{Hard Gore}

Film Despentes i Trinh Thi próbuje przekroczyć spektakl, fetyszyzowane zewnętrze, otwierając się na możliwość transcendentnego i transparentnego ucieleśnienia, takiego, w którym to, co na zewnątrz, nie jest oddzielone od wnętrza, w którym ciało jest jednocześnie czystą zewnętrznością i wnętrzem. Żeby do tego doszło, stare podziały binarne muszą ulec zatarciü ${ }^{34}$.

Ta interpretacja Gwattu (Baise-moi, Francja 2000) koresponduje z postulatami stawianymi przez Grosz (dwa centralne rozdziały książki Volatile Bodies tytułuje Inside Out i Outside In). Ponadto film wywołał tak duże kontrowersje przez zawartość eksplicytnych scen przemocy i seksu, rozpoczynając przy okazji środowiskową batalię o wycofanie kategorii $\mathrm{X}^{35}$, że można go uznać za oficjalną inaugurację nowej estetyki.

Gwalt to efekt współpracy trashowej pisarki Virginie Despentes ${ }^{36}$ i aktorki porno Coralie Trihn Thi. Reżyserki zaangażowały gwiazdy przemysłu pornograficznego i już na tym poziomie w otwarty sposób powiązały swój film z hard core'em. Gwatt to opowieść o dwóch Francuzkach arabskiego pochodzenia, prostytutce i aktorce porno, które nie mając nic do stracenia, podróżują po kraju, zabijają, kradną, piją, zażywają kokainę i uprawiają seks z „,upolowanymi” mężczy-

${ }^{33}$ M. Rogowska-Stangret, op. cit.

${ }^{34}$ M. Beugnet, Cinema and Sensation: French Film..., s. 52.

${ }^{35}$ Kontrowersje wokół premiery Gwattu szczegółowo opisuje Leila Wimmer (zob. L. Wimmer, Sex and Violence from a Pair of Furies: The Scandal of „Baise-moi”, [w:] The New Extremism...) oraz Martin Barker (M. Barker, ,, Typically French”? Mediating Screen Rape to British Audiences, [w:] Rape in Art Cinema, red. D. Russell, London 2010).

${ }^{36}$ W Polsce wydano dwie pierwsze części trylogii Vernon Subutex oraz Teorię King Konga. 
znami. Twórczynie wpisały tę narrację w formułę gatunków cielesnych — skupiły się na kobiecych ciałach, jednak wydostały je spod kontroli mężczyzn i ich przyjemności. Despentes od wielu lat postuluje przejęcie pornografii przez kobiety ${ }^{37}$, uważając — podobnie jak Angela Carter — że jest ona zdominowana przez męskie pożądanie: kiedy służy ona „wzmacnianiu systemu wartości i idei w danym społeczeństwie, jest tolerowana; a kiedy tego nie robi, jest zakazywana" ${ }^{\text {"3 }}$. Właśnie film duetu, śmiało flirtujący $\mathrm{z}$ reprezentacją nieposkromionego pożądania, aktywnego inicjowania zbliżeń seksualnych, a także meat shotów, wydłużający sceny seksu do tego stopnia, że zaczynają mieć autonomiczne znaczenie, prawie padł ofiarą takiej cenzury.

Twierdzono również, że kontrowersje musiało budzić wyeksponowanie różnicy genderowej, etnicznej i klasowej (obie bohaterki związane są z banlieu) i zaprezentowanie ich jako śmiercionośnego zagrożenia dla rzekomo jednolitego społeczeństwa francuskiego. Jednak koncepcja zemsty Innego zostaje osłabiona przez kompletnie przypadkowy dobór ofiar. Racjonalizacja zostaje całkowicie odrzucona. Na pytanie, dlaczego molestują i mordują ludzi, jedna z bohaterek odpowiada po prostu: „Bo możemy”. „Znana tradycja filmowa wyjaśniająca (i thumacząca) kobiecą agresję doświadczeniem przemocy seksualnej [...] zostaje kategorycznie odrzucona" 39 . Manu zostaje zgwałcona, jednak nie podchodzi do zdarzenia emocjonalnie, nie traktuje siebie jako ofiary i na pewno nie definiuje siebie poprzez pryzmat tego zdarzenia ${ }^{40}$. Tym sposobem początkowa sugestia formuły rape-and-revenge movie, którą dodatkowo wspiera polski tytuł, jest jedynie grą z oczekiwaniami widza, a jej konsekwencje ukazują subwersywność tego filmu. Po pierwsze, jeśli gwałt jest głównym tematem, to raczej ten symboliczny, jaki na pełnym samozadowolenia społeczeństwie mogą uczynić dwa zbuntowane „ciała”. Po drugie, film w wielu scenach na poziomie fabularnym i formalnym podkreśla swój metatekstualny wymiar. Joanna Bourke zwróciła uwagę, że przemoc w wykonaniu mężczyzn jest ukazywana realistycznie (co podkreśla nawet stosowanie w scenie gwałtu długich ujęć), z kolei kobieca przemoc jest stylizowana poprzez ciąg autoreferencyjnych odniesień ${ }^{41}$. Sprawia to, że film zarówno podkreśla swój fantazmatyczny charakter ${ }^{42}$, jak i staje się wypowiedzią na temat sposobów ukazywania gwałtu w kinie.

${ }^{37}$ Despentes wyreżyserowała później Mutantki (Mutantes, Francja 2009), dokument o feministycznej pornografii.

${ }^{38}$ Podaję za: L. Wimmer, op. cit., s. 131.

39 J. Bourke, Sexual Trauma and Jouissance in „Baise-moi”, [w:] Rape in Art Cinema..., s. 187.

40 Podobnie gwałt ukazany został w Mojej siostrze (À ma soeur!, reż. Catherine Breillat, Francja-Włochy 2001).

${ }^{41}$ Zob. J. Bourke, op. cit., s. 190.

42 Także poprzez zastosowanie „niechlujnej”, ziarnistej estetyki wideo, którą można by było interpretować w kategoriach haptycznej wizualności Laury Marks, multiplikując wymiary cielesnego zaangażowania widza. 
Ten drugi aspekt jest rozwijany nie tylko poprzez odwołania do wspomnianej już konwencji filmowego slashera, lecz także do filmów ukazujących przemoc wobec kobiet jako arthouse'owy gimmick, perwersyjnie normalizujących gwałt jako narracyjny wątek i stylistyczną możliwość. W filmach gwałcona kobieta zazwyczaj zostaje sprowadzona do roli przedmiotu, pozbawiona jest tożsamości i sprawczości, za to silnie podkreślana jest jej fizyczność, która momentalnie zamienia się w więzienie; z kolei gwałty dokonywane na mężczyznach koncentrują się — jak w Uwolnieniu (Deliverance, reż. John Boorman, USA 1972) — na świadkach zdarzeń, na ich pełnym wstydu spojrzeniu, a także uciekają się do feminizacji ofiary. Sposób traktowania ciała w scenach gwałtu akcentuje także różnice wrażliwości społecznej w wypadku reżyserów i reżyserek związanych z ekstremizmem francuskim - przemoc seksualna wobec kobiet pojawia się w filmach Noé (przede wszystkim w Nieodwracalnym [Irréversible, Francja 2002]), Grandrieux (wspomniane Sombre, ale zwłaszcza La vie nouvelle [Francja 2002]) i Dumonta i jedynie ten ostatni stara się być w pełni świadomy dyskursu wokół przedstawiania gwałtu w kinie, co sugerują eliptyczne, pełne empatii przedstawienia w Ludzkości czy Flandrii, lecz także odwrócenie „ról” w Twentynine Palms. Punktem kulminacyjnym jest tu gwałt dokonany na głównym bohaterze przez nieznanych mężczyzn, zmuszających partnerkę ofiary do oglądania całej sceny, przez co film obnaża opresyjność wcześniejszych stosunków seksualnych pary, naznaczonych przez męską przemoc i dominację ${ }^{43}$.

Problem kobiecej agresji i estetykę gore rozwijają dwie reżyserki eksplorujące niezwykle wisceralną formułę horroru kanibalistycznego - Claire Denis w Gtodzie miłości (Trouble Every Day, Francja-Niemcy-Japonia 2001) oraz Julia Ducournau w Mięsie (Grave, Włochy-Francja-Belgia 2016). W pierwszym filmie dwóch neurobiologów, Amerykanin Shane Brown i Francuz Léo Semeneau, prowadzi badania w Gujanie Francuskiej, w których efekcie odkrywają wirusa wywołującego nieposkromione pożądanie seksualne prowadzące do żądzy krwi. Żona Semeneau, Coré, i Shane są zarażeni. Amerykanin ukazywany jest w czasie przemiany, jednak to kobietę poznajemy jako mięsożernego drapieżnika. Jej kanibalizm zrodzony na miejscu pożądania odwraca role płciowe, w których to ciało kobiety jest zwykle eksploatowane. Tutaj staje się do pewnego stopnia biologiczną lekcją pokory, co podkreśla dodatkowo wątek pamięci kolonialnej przeszłości Francji (w przypadku Shane'a w grę wchodzi raczej amerykański imperializm i neokolonializm). Denis przedstawia ciało w stanie metamorfozy jako coś płynnego, niemal bezkształtnego, co mutuje w niekontrolowany sposób i wydostaje się poza racjonalne dyskursy nowoczesności ${ }^{44}$.

${ }^{43}$ Zob. szerzej L. Coulthard, Uncanny Horrors: Male Rape in Bruno Dumont's "Twentynine Palms", [w:] Rape in Art Cinema...

44 Opis tych fluktuacji można znaleźć w: M. Beugnet, Cinema and Sensation: French Film... Ciekawym rozwinięciem upłynnienia cielesnych granic jest Ewolucja (Évolution, reż. Lucile Ha- 
W dwie kluczowe role wcielili się Béatrice Dalle i Vincent Gallo, aktorzy słynący ze swoich transgresyjnych ról. Podobnie autotematyczny casting został zastosowany w Mięsie, gdzie Laurent Lucas wcielił się w postać ojca głównej bohaterki. Jego ekranowa obecność nie tylko automatycznie plasuje film Ducournau w ramach ekstremizmu, gdyż aktor kojarzony jest z rolami u Mariny de Van, Fabrice'a du Welza czy Bertranda Bonello, lecz ma także na tyle rozpoznawalną twarz, że widz od razu zwraca uwagę na niepokojącą bliznę nad jego górną wargą. Podobnie antycypującą funkcję pełni inicjalna scena powodowania wypadku samochodowego przez spacerującą poboczem kobietę (która później okazuje się główną bohaterką, Justine), wibrujący dźwięk, niepokojące zestawianie hałasu z wyciszeniem (Lisa Coulthard uważa, że taki zabieg ma haptyczny, cielesny wymiar $^{45}$ ), gwałtownie pojawiająca się krwistoczerwona plansza z tytułem czy komiczny jump scare, kiedy Justine zostaje przestraszona przez siostrę, Alex, podświetlającą sobie twarz latarką. Te elementy wprowadzają odbiorców w konwencje horroru. Film rozpoczyna się odwożeniem bohaterki przez rodziców na studia - ma uczyć się weterynarii w tej samej akademii co siostra. Cała rodzina (poza Alex) to wegetarianie, więc krwawe kotowanie na uczelni - Justine zostaje zmuszona do zjedzenia nerki królika - jest dla dziewczyny traumatycznym przeżyciem. Dostaje silnej wysypki, może zrywać płaty skóry, lecz to tylko początek jej przemiany. Budzi się w niej bowiem głód mięsa, szybko okazujący się kanibalistycznym pociągiem.

Ducournau tworzy na kanwie konwencji horroru opowieść o dojrzewaniu i poszukiwaniu tożsamości. Justine początkowo zestawiana jest z obrazami cierpiących, więzionych zwierząt, co podkreśla jej zachowawczość, nieśmiałość i uśpienie cielesnych potrzeb. Na studiach konfrontuje się z nieprzyjaznymi rówieśnikami (w jednej ze scen starsza studentka każe jej ubrać pieluchę, co symbolicznie zaznacza jej niedojrzałość), musi sprostać oczekiwaniom rodziców i nauczycieli, nie dba o swoją powierzchowność, ignorując wszelkie zabiegi upiększające, i - jak wyznaje lekarce — jest dziewicą. Smak mięsa doprowadza do przebudzenia, przed którym się broni - negowanie zachodzących w niej przemian początkowo nadaje jej animalistyczne cechy: przestaje kontrolować swój gniew, wymiotuje włosami, uwodzi swojego współlokatora-geja, a następnie w czasie orgazmu musi zatopić zęby we własnym ciele, żeby go nie skrzywdzić. Pożądanie (wiele scen podkreśla female gaze) miesza się z niezaspokojonym głodem. Przewodnikiem w tym procesie zostaje nieodpowiedzialna starsza siostra — kiedy Justine odmawia podporządkowania się swoim instynktom, Alex upokarza ją w chwili alkoholowego upojenia, kusząc ciałem w kostnicy. Dochodzi do zażartej walki między dziewczynami gryzącymi się nawzajem, na koniec jednak,

dzihalilovic, Francja-Belgia-Hiszpania 2015), który to film jest wariacją na temat rozwoju morskich (i nie tylko) organizmów, lecz także refleksją nad rozmnażaniem i macierzyństwem.

45 Zob. L. Coulthard, Haptic aurality: Resonance, listening and Michael Haneke, „Film-Philosophy" 2012, nr 16. 
połączone wspólnym losem i siostrzaną bliskością, opatrują sobie rany. Ostatecznie Mięso do opowieści o cielesnej inicjacji w kobiecość okazuje się wykorzystywać konwencje gore.

Kobiece pożądanie staje się również tematem Pod moją skóra (Dans ma peau, Francja 2002) Mariny de Van. Narracja koncentruje się na postaci Esther pracującej w paryskiej agencji reklamowej jako analityk, pnącej się po szczeblach kariery i szukającej mieszkania dla siebie oraz swojego partnera. Funkcjonuje ona w środowisku zdominowanym przez mężczyzn. Na jednej z imprez firmowych, na których musi się pojawić, aby zapewnić sobie awans, przewraca się i poważnie rani się w nogę. Początkowo nie czuje bólu, co uświadamia jej obcość własnego ciała. W dosłowny sposób obrazuje to scena biznesowej kolacji, kiedy bohaterka wyobraża sobie defragmentację: jej lewe przedramię odłącza się od reszty ciała. Przejmuje zatem kontrolę nad nieposłusznym korpusem, penetrując to, co kryje się pod skórą.

Body integrity identity disorder, jednostka chorobowa opisująca autodestrukcyjne zaburzenia bohaterki, zdaje się wynikać z określonej pozycji kobiet w społeczeństwie. Dla Esther zaburzenie ma również znaczenie transgresyjne i tożsamościotwórcze. Z jednej strony, rozcinając swoją skórę, Esther niszczy fantazje erotyzujące kobietę, a przez to i przyjemność czerpaną przez mężczyzn. Z drugiej, ukierunkowuje pożądanie ku sobie. Jej postępowanie jest wsobne, całkowicie autonomiczne. Takie radykalne odwrócenie perspektywy sugeruje już początek filmu, w którym użyte są zdjęcia negatywowe i split-screen. Pod moją skórą zawiera zatem elementy każdego z opisywanych przez Williams gatunków cielesnych. Intensywne emocje wstrętu czy obrzydzenia upodabniają film do body horror. Graficzne przedstawienie ciała kobiecego to konwencja znana z filmów pornograficznych. Z nich też pochodzi fantazja o spotkaniu i uwiedzeniu — tak bowiem można odczytywać proces poznawania swojego ciała, dosłownego zanurzania się w nim. Taka struktura przybliża film de Van do melodramatu. W fabule dostrzegamy kolejne elementy: miłość od pierwszego wejrzenia, obecność „fatum”, uczucie tak silne, że niedające się pokonać, rozpoznany przez Williams aspekt masochistyczny ${ }^{46}$, a nawet obecność przeszkód (praca zawodowa, w której liczy się prezencja, i zazdrosny partner) oraz nacisk na repetytywność i spektakl. Sceny „spotkań" z ciałem również mają genezę romansową, nawet na poziomie ikonograficznym (ciemne pomieszczenia czy pokoje hotelowe jako miejsca schadzek). Za pomocą wykorzystania tych konwencji de Van bada dystans między ciałem a podmiotem, eksplorując własną cielesność - wciela się bowiem w główną rolę.

$$
* * *
$$

Bodaj najważniejszą i najlepiej znaną „ekstremistką” jest Catherine Breillat, od lat 70. XX wieku rozwijająca w swoich filmach dyskurs związany z kobie-

${ }^{46}$ L. Williams, Film bodies, s. 9. 
cą seksualnością, nierzadko posługując się konwencjami filmów pornograficznych, a raczej ich rewersem: obnaża mechanizmy uwodzenia i arbitralność formuł opowiadania, rezygnuje z meat shotów, upodmiotawia kobiety, jednocześnie nie odbierając im prawa do autoekspresji cielesnej i erotycznej, przywraca im fizjologiczny wymiar. Filmy Breillat stanowią kontekst, wewnątrz którego rozwija się feministycznie ukierunkowany odłam nowego ekstremizmu francuskiego. Przykładowo w Romansie (Romance, Francja 1999) główna bohaterka, Marie, aktywnie poszukująca spełnienia erotycznego, opowiada o wyobrażonym domu publicznym. Dla klientów dostępna jest tylko część kobiety od pasa w dół. Mężczyźni krążą wokół, wybierając najatrakcyjniejsze łona. Druga część ciała kobiet znajduje się za ścianą i uczestniczy w rodzinnym życiu jako żona i matka.

Ciało obnażane przez konwencje opisywanych przez Williams gatunków jawi się jako akt polityczny, a same związane z nimi konwencje narracyjne i ikonograficzne nabierają krytycznego, transgresyjnego wymiaru. Posługując się silnie kobiecą perspektywą, reżyserki związane z ekstremizmem francuskim eksponują w swoich somatekstach potrzeby kobiet oraz opresyjność patriarchalnego społeczeństwa, budując pomost między kinem doznań a feminizmem korporalnym i nieustannie negocjując znaczenie relacji ,waginy i twarzy" ${ }^{\prime 7}$.

\section{Bibliografia}

\section{Źródla}

Altman R., Gatunki filmowe, przeł. M. Zawadzka, Wydawnictwo Naukowe PWN, Warszawa 2012.

Barker J.M., The Tactile Eye: Touch and the Cinematic Experience, University of California Press, Berkeley-Los Angeles-London 2009.

Barker M., "Typically French"? Mediating Screen Rape to British Audiences, [w:] Rape in Art Cinema, red. D. Russell, Continuum, London 2010.

Beugnet M., Cinema and sensation: Contemporary French film and cinematic corporeality, „Paragraph” 2008, $\mathrm{nr} 2$.

Beugnet M., Cinema and Sensation: French Film and the Art of Transgression, Edinburgh University Press, Edinburgh 2007.

Brook P., The Melodramatic Imagination: Balzac, Henry James and the Mode of Excess, London 1976.

Carroll N., Filozofia horroru albo paradoksy uczuć, przeł. M. Przylipiak, słowo/obraz terytoria, Gdańsk 2004.

Clover C.J., Her body, himself: Gender in the slasher film, „Representations” 1987, nr 20.

Coulthard L., Haptic aurality: Resonance, listening and Michael Haneke, „Film-Philosophy” 2012, nr 16.

Frey M., Extreme Cinema: The Transgressive Rhetoric of Today's Art Film Culture, Rutgers University Press, New Brunswick-New Jersey-London 2016.

Grosz E., Bodies-Cities, [w:] eadem, Space, Time, and Perverision: Essays on the Politics of Bodies, Routledge, New, York-London 1995.

Johnston C., Kino kobiece jako kino buntu, przeł. A. Helman, „Film na Świecie” 1990, nr 1.

${ }^{47}$ Cytat z Prawdziwej dziewczyny (Une vraie jeune fille, Francja 1976). 
Langford B., Film Genre: Hollywood and Beyond, Edinburgh University Press, Edinburgh 2005.

Massumi B., Autonomia afektu, przeł. A. Lipszyc, ,Teksty Drugie” 2013, nr 6.

Mulvey L., Kino zwtoki, przeł. J Klimek, J. Majmurek, [w:] eadem, Do utraty wzroku. Wybór tekstów, Wydawnictwo Nowe Horyzonty, Korporacja Ha!art, Kraków-Warszawa 2010.

Mulvey L., Przyjemność wzrokowa a kino narracyjne, przeł. J. Mach, [w:] eadem, Do utraty wzroku: Wybór tekstów, red. K. Kuc, L. Thompson, Wydawnictwo Nowe Horyzonty, Korporacja Ha!art, Kraków-Warszawa 2010.

Nichols B., Film theory and the revolt against narratives, [w:] Reinventing Film Studies, red. C. Gledhill, L. Williams, Arnold, London-New York 2000.

Rogowska-Stangret M., Ciało - poza Innościa i Tożsamościa, słowo/obraz terytoria, Gdańsk 2016.

Shaviro S., The Cinematic Body, University of Minnesota Press, Minneapolis 1993.

Szcześniak M., Symulakryczna przyjemność. Obrazykobiecejprzyjemności w filmach pornograficznych, „Kultura Popularna” 2009, nr 1.

Williams L., Film Bodies: Gender, Genre, and Excess, „Film Quarterly” 1991, nr 4.

Williams L., Hard core: Władz, przyjemność i , szaleństwo widzialnego”, przeł. J. Burzyńska, I. Hansz, M. Wojtyna, słowo/obraz terytoria, Gdańsk 2012.

Wimmer L., Sex and Violence froma Pair of Furies: The Scandal of „Baise-moi”, [w:] The New Extremism in Cinema: From France to Europe, red. T. Horeck, T. Kendall, Edinburgh University Press, Edinburgh 2011.

\section{Źródła internetowe}

Chandler D., An introduction to genre theory, http://www.aber.ac.uk/media/Documents/intgenre/ chandler_genre_theory.pdf.

Erensoy Ş.F., The reflection of contemporary anxieties in the contemporary French horror cycle, 2017, $\mathrm{http}: / /$ framescinemajournal.com/article/the-reflection-of-contemporary-anxieties-in-the-contemporary-french-horror-cycle/.

Quandt J., Flesh and blood: Sex and violence in recent French cinema, 2004, https://www.thefreelibrary.com/Flesh $+\% 26+$ blood $\% 3 \mathrm{~A}+\mathrm{sex}+\mathrm{and}+$ violence $+\mathrm{in}+$ recent + French + cinema.-a0113389507.

\section{Filmografia}

35 kieliszków rumu (35 rhums), reż. C. Denis, Francja-Niemcy 2008.

Blady strach (Haute Tension), reż. A. Aja, Francja-Włochy-Rumunia 2003.

Ewolucja (Évolution), reż. L. Hadzihalilovic, Francja-Belgia-Hiszpania 2015.

Flandria (Flandres), reż. B. Dumont, Francja 2006.

Frontière(s), reż. X. Gens, Francja-Szwajcaria 2007.

Głód miłości (Trouble Every Day), reż. C. Denis, Francja-Niemcy-Japonia 2001.

Gwalt (Baise-moi), reż. V. Despentes, C. Trinh Thi, Francja 2000.

Jutro będziemy szczęśliwi (Demain tout commence), reż. H. Gélin, Francja-UK 2016.

Love, reż. G. Noé, Francja-Belgia 2015.

Ludzkość (L'humanité), reż. B. Dumont, Francja 1999.

Mięso (Grave), reż. J. Ducournau, Włochy-Francja-Belgia 2016.

Moja siostra (À ma soeur!), reż. C. Breillat, Francja-Włochy 2001.

Mutantki (Mutantes), reż. V. Despentes, Francja 2009.

Najście (À l'intérieur), reż. A. Bustillo, J. Maury, Francja 2007.

Nieodwracalne (Irréversible), reż. G. Noé, Francja 2002. 
Oczy bez twarzy (Les yeux sans visage), reż. G. Franju, Francja-Włochy 1960.

Pieśń mitości (Un chant d'amour), reż. J. Genet, Francja 1950.

Pod moją skóra (Dans ma peau), reż. M. de Van, Francja 2002.

Romans (Romance), reż. C. Breillat, Francja 1999.

Sombre, reż. P. Grandrieux, Francja 1998.

Sprawa Kramerów (Kramer vs. Kramer), reż. R. Benton, USA 1979.

Twentynine Palms, reż. B. Dumont, Francja-Niemcy-Włochy 2003.

Uwolnienie (Deliverance), reż. J. Boorman, USA 1972.

La vie nouvelle, reż. P. Grandrieux, Francja 2002.

Weekend (Week-end), reż. J.-L. Godard, Francja-Włochy 1967.

Wierzaca (Hadewijch), reż. B. Dumont, Francja 2009.

Żywot Jezusa (La vie de Jésus), reż. B. Dumont, Francja 1997.

\section{Liberté, Égalité, Sororité: Female body genres and the women of the New French Extremity}

\section{Summary}

In the essay Film Bodies: Gender, Genre, and Excess, Linda Williams coins the concept of body genres. These genres include melodrama, horror and porn, which are linked through their impact on the spectator's body and intensifying viewing experiences. According to Williams, these three film genres emphasize the notion of spectacle, but they place the female body in its centre. The female body is moving and is being moved, which causes its vulnerability to the hegemony of the male gaze. But we can conduct research from a feminist perspective and find films that simultaneously tell about a visceral excess and develop an intellectual transgression through the body. The best example of this tendency is the New French Extremity, precisely the female directors such as Catherine Breillat, Mariny de Van or Virginie Despentes. They maximize the somatic spectacle in their films, which annihilates the pleasure that the male spectator derives from the fetishized female body. 